\title{
Digit and Ungual Morphology Suggest Adaptations for Scansoriality in the Late Carboniferous Eureptile Anthracodromeus longipes
}

\author{
Arjan Mann ${ }^{1 *}$, Thomas W. Dudgeon ${ }^{2,3}$, Amy C. Henrici ${ }^{4}$, David S Berman ${ }^{4}$ and \\ Stephanie E. Pierce ${ }^{1}$
}

${ }^{1}$ Museum of Comparative Zoology and Department of Organismic and Evolutionary Biology, Harvard University, Cambridge, MA, United States, ${ }^{2}$ Department of Ecology and Evolutionary Biology, University of Toronto, Toronto, ON, Canada, ${ }^{3}$ Department of Natural History, Royal Ontario Museum, Toronto, ON, Canada, ${ }^{4}$ Section of Vertebrate Paleontology, Carnegie Museum of Natural History, Pittsburgh, PA, United States

OPEN ACCESS

Edited by:

Jörg Fröbisch,

Museum of Natural History Berlin

(MfN), Germany

Reviewed by:

David Dilkes,

University of Wisconsin-Oshkosh,

United States

Virginia Abdala,

IBN CONICET-UNT, Argentina

Tracy Joseph Thomson,

University of California, Davis,

United States

*Correspondence:

Arjan Mann

arjan.mann@carleton.ca

Specialty section:

This article was submitted to

Paleontology,

a section of the journal

Frontiers in Earth Science

Received: 02 March 2021

Accepted: 17 May 2021

Published: 07 June 2021

Citation:

Mann A, Dudgeon TW, Henrici AC, Berman DS and Pierce SE (2021) Digit

and Ungual Morphology Suggest Adaptations for Scansoriality in the

Late Carboniferous Eureptile

Anthracodromeus longipes.

Front. Earth Sci. 9:675337.

doi: 10.3389/feart.2021.675337
A new skeleton of the exceedingly rare, late Carboniferous eureptile Anthracodromeus longipes (Carroll and Baird, 1972), reveals the presence of a reduced phalangeal count in the manus and pedes and uniquely recurved unguals. With these data, we quantitatively evaluate the locomotor ecology of Anthracodromeus using morphometric analyses of the phalangeal proportions, ungual curvature, and ungual shape. Our findings indicate that the anatomy of Anthracodromeus likely facilitated scansorial clinging to some degree via distally recurved unguals and increased surface area of the large manus and pes. This suggests that Anthracodromeus was among the earliest amniotes to show climbing abilities, pushing back the origins of scansoriality by at least 17 million years. It further suggests that scansoriality arose soon after the origin of amniotes, allowing them to exploit a wide range of novel terrestrial niches.

Keywords: Carboniferous (= Mississippian Pennsylvanian), claw morphology, morphometrics, digit reduction, reptile anatomy, scansorial

\section{INTRODUCTION}

Scansoriality, or the capability to climb, is a common adaptation in living tetrapod groups. Scansoriality can be further distinguished into a number of subcategories, including rock and wall climbers as well as more arboreal (i.e., climbing in trees and tree-like plants) forms. From an ecological perspective, climbing opens new niches and confers a novel means of escaping groundbased predators (Fröbisch and Reisz, 2009; Fischer et al., 2010). Among amniotes, one of the most common characteristics of scansorial forms is the possession of recurved claws. This morphology has been noted in the fossil record as early as the mid-Carboniferous. One claw-bearing taxon is Anthracodromeus longipes (Carroll and Baird, 1972), which was regarded as an arboreal form based upon a single specimen from the classic Coal Measure locality of Linton, Ohio (Carroll and Baird, 1972). While once considered part of the paraphyletic Protorothyrididae, Anthracodromeus is currently considered a basal eureptile with close relationships to the similarly-aged Cephalerpeton and later Early Permian Protorothyris (Mann et al., 2019; Ford and Benson, 2020). In their original description, Carroll and Baird recognized the elongated manus and pes of Anthracodromeus but did not elaborate on their ecological significance. More recently, Spindler et al. (2018) proposed that Anthracodromeus was adapted for scansoriality through phalangeal grasping; that is, the animal used 
its elongated digits to grasp onto tree branches of different diameters. These interpretations are based upon the type specimen (AMNH FARB 6940), which unfortunately has poorly preserved unguals (the distal-most phalanges that support the keratinous claws). In addition, no morphometric analysis has been attempted to determine if the unguals and manual proportions of Anthracodromeus are consistent with those of known climbing taxa.

Here, we consider the ecological aspects of Anthracodromeus based upon a recently recovered specimen (CM 81532) from Linton, Ohio. In addition to revising the diagnosis for Anthracodromeus longipes, we provide a thorough comparative description of the new material that includes a well-preserved, ungual-bearing manus and pedes that reveal reduced phalangeal counts (hypophalangy) compared to other early amniotes. We also present morphometric comparisons of the phalangeal proportions and ungual curvature of this specimen using three prior datasets (Fröbisch and Reisz, 2009; Birn-Jeffery et al., 2012; Thomson and Motani, 2021), providing a quantitative basis for evaluating the climbing capabilities of Anthracodromeus. The results support scansorial abilities, likely through clinging not grasping, and provide novel insights into the ecological capabilities of one of the earliest-known amniotes.

\section{MATERIALS AND METHODS}

\section{Anatomical Analysis}

Specimens were studied at the following institutions: American Museum of Natural History (AMNH FARB), New York; Carnegie Museum of Natural History (CM), Pittsburgh; Field Museum of Natural History (FMNH), Chicago; Canadian Museum of Nature (CMN), Ottawa; Museum of Comparative Zoology at Harvard University (MCZ), Cambridge; Redpath Museum (RM), Montreal; and Yale Peabody Museum (YPM), New Haven.

The new specimen (CM 81532) was compared to the holotype of Anthracodromeus longipes (AMNH FARB 6940; Supplementary Figures S1-S3) and to a referred specimen (CM 25282, see Reisz and Baird, 1983). The following basal eureptiles, including all known "protorothyridids", likewise were compared based upon original material and casts: Protorothyris, Hylonomus, Cephalerpeton, Paleothyris, Coelostegus, Brouffia, Captorhinus, Romeria, and Rhiodenticulatus. In addition, CM 81532 was compared to relatively complete Permo-Carboniferous parareptiles, including Erpetonyx, Eudibamus, Delorhynchus, and Mesosaurus tenuidens. Comparisons among synapsids focused on slender forms, such as varanopids, and on the early arboreal therapsid Suminia to survey digit elongation and other scansorial adaptations.

CM 81532 was photographed with a Nikon D700 camera with an AF-S NIKKOR 24-85 mm lens. Photographs in Figure 2 were made with a Canon EOS 6D with a Canon ef $100 \mathrm{~mm}$ macro lens. Because of the fragile condition of CM 81532, latex peels were not attempted. Thus, specimen illustrations were made from the actual specimen that is a natural mold and from photographs of the specimen. Three-dimensional osteological details were reconstructed on the basis of direct observation and the image inversion option in Adobe Photoshop CS6. Lastly, it should be noted that the biological left and right sides of a fossil impression are opposite of what is directly observed in the original cannelcoal block and the accompanying illustrations.

\section{Morphometric Analyses Manual Proportions}

To assess similarities between Anthracodromeus and other extant and extinct amniotes, we measured its manual proportions (the length of the metacarpal, proximal phalanx, and penultimate phalanx of the third digit relative to the length of their sum; see Supplementary Table S4 for measurements) of digit III and included it in the extant dataset of Fröbisch and Reisz (2009). This dataset consists primarily of extant terrestrial and arboreal amniotes, along with some extinct terrestrial synapsids and the arboreal synapsid Suminia (see Fröbisch and Reisz 2009 for the complete taxonomic sample). The data were plotted in a ternary plot using the 'ggtern' function from the R package ggtern v.3.3.0 (Hamilton and Ferry, 2018) and visualized by means of ggplot2 v.3.3.2 (Wickham, 2016) in R (v.3.6.1; Core Team, 2019). Convex hulls of extant taxa were generated using the 'geom_encircle' function from the R package ggalt v.0.4.0 (Rudis et al., 2017).

\section{Ungual Curvature}

To evaluate if the ungual curvature of Anthracodromeus is consistent with that of extant scansorial amniotes, we compared the ungual curvature and ungual thickness of Anthracodromeus to the comparative claw dataset of BirnJeffery et al. (2012), using the methods of Feduccia (1993; see Supplementary Figure S5 for a detailed breakdown of the measurement protocol and Supplementary Table S6 for data collected). See Birn-Jeffery et al. (2012) for the complete taxonomic sample. We also used these methods to calculate ungual curvature and relative thickness for sixteen other extinct amniotes to determine whether the unguals of Anthracodromeus are similar to coeval amniotes (Ascendonanus nesterli, Spindler et al., 2018; Batropetes fritschi, Carroll 1964; Cabarzia trostheidei, Spindler et al., 2018; Captorhinus aguti, Holmes, 2003; Cotylorhynchus romeri, Maddin and Reisz, 2007; Dimetrodon limbatus, Maddin and Reisz, 2007; Edaphosaurus boanerges, Maddin and Reisz, 2007; Eocasea martini, Reisz and Fröbisch, 2014; Erpetonyx arsenaultorum, Modesto et al., 2015; Haptodus garnettensis, Maddin and Reisz, 2007; Martensius bromackerensis, Berman et al., 2020; Mesenosaurus romeri, Spindler et al., 2018; Palaeohatteria longicaudata, Spindler et al., 2018; Spinoaequalis schultzei, deBraga and Reisz, 1995; Suminia getmanovi, visual observation of specimen one on block PIN 2212/116, and Varanops sp., Maddin and Reisz, 2007). Some of these taxa possess a prominent flexor tubercle, and the apex of the tubercle was used as the basal position of the ventral arc for these taxa, because it marked the approximate position where the keratinous claw ended. For taxa lacking a flexor tubercle, the proximal-most portion of the ventral ungual arc was used for the basal position because the extent of the keratinous sheath could 
not be determined. See Discussion for a review of the issues and caveats associated with comparing boney unguals to keratinous claws.

Claw and ungual curvature and thickness measurements were read into R (v.3.6.1; Core Team, 2019) for comparison. Outer claw curvature and inner claw curvature were then plotted against relative claw thickness for visualization using the function 'ggplot' in the R package ggplot2 v.3.3.2 (Wickham, 2016), along with outer claw curvature against inner claw curvature. Although there are general trends in the dataset, Birn-Jeffery et al. (2012) found that there were no statistically significant differences in claw curvature between groups when phylogeny was considered, and as such, we do not perform statistical comparisons to determine the ecological habits of Anthracodromeus. Instead, we used these data to determine whether the ungual curvature of Anthracodromeus is overall consistent with scansorial capabilities (see Discussion for a detailed review of the limitations of these methods), and to determine whether the unguals share similarities with other known coeval amniotes.

\section{Ungual Shape and Functionality}

To quantitatively evaluate the shape and functionality of the unguals of Anthracodromeus, we compared its ungual morphology with those of the extant amniotes from Thomson and Motani (2021). See Discussion for a review of the issues and caveats associated with comparing boney unguals to keratinous claws. Although Thomson and Motani (2021) used 18 linear, angular, and cross-sectional area measurements to quantify keratinous claw shape, we solely used the linear measurements here due to preservation limitations. Therefore, the final dataset used in this study consisted of 11 measurements quantifying claw shape (Supplementary Information S7-S9). These measurements were calculated for the ungual on digit III of the pes of Anthracodromeus (CM 81532) following the methods of Thomson and Motani (2021) via photographs of the specimen. Digit three was chosen because it is best preserved in this specimen and is clearly visible in lateral view. See Supplementary Information S7 for a detailed description of the measurements and Supplementary Table S9 for measurements collected from CM 81532.

Raw measurements were analyzed in R v.3.6.1 (Core Team, 2019) following the code of Thomson and Motani (2021). The two outlier taxa (Gopherus and Cyclopes) were removed from the dataset prior to the analyses so as not to bias the results. Data were $\log$ transformed to normalize the data, and, to remove size and phylogenetic signal, the extant taxa subjected to phylogenetic generalized least squares regression (PGLS) using the procD.pgls function from the R package geomorph v.3.3.1, with dorsal curve length as the regressor variable. The phylogeny for the PGLS came from Thomson and Motani (2021). The log-transformed ungual measurements of Anthracodromeus were then projected into the PGLS using the 'predict' function from the stats package (Core team, 2019). Residuals for the extant taxa and Anthracodromeus were then subjected to a principal components analysis (PCA) using the 'princomp' function in $\mathrm{R}$ (Core Team, 2019) to determine the major axes of claw and ungual shape variation. Principal component (PC) axes were visualized using the 'ggplot' function from the R package ggplot2 v.3.3.2 (Wickham, 2016).

The residuals for the extant taxa were also subjected to linear discriminant analysis (LDA) using the 'lda' function in the $\mathrm{R}$ package MASS v.7.3.51.6 (Venables and Ripley, 2002) to determine the major axes of between-group variation in the extant taxa, and estimate group classifications for Anthracodromeus. The functional groups for the extant taxa in the LDA were taken from Thomson and Motani (2021), and are defined as follows: amplectorial (grasping), cursorial (running or hopping), generalist (multipurpose), gryporial (hook-and-pull digging), scalporial (scratch digging), scansorial (climbing), suspensorial (hanging), and tenasorial (grappling). The misidentification rate of the LDA was calculated using a confusion matrix through the code of Thomson and Motani (2021). The PGLS residuals for Anthracodromeus were then projected into the LDA using the function 'predict.lda' from the $\mathrm{R}$ package MASS (Venables and Ripley, 2002) using uninformed priors (all groups have equal probability), providing posterior probabilities for the assignment of Anthracodromeus to each functional group. Linear discriminant (LD) axes were visualized using the 'ggplot' function from the $\mathrm{R}$ package ggplot2 (Wickham, 2016) with convex hulls plotted using the 'geom_mark_hull' function from ggforce v.0.3.2 (Pedersen, 2020).

\section{RESULTS}

\section{Systematic Paleontology}

Amniota Haeckel, 1866.

Eureptilia Olson, 1947.

Anthracodromeus Carroll and Baird, 1972.

Anthracodromeus longipes Carroll and Baird, 1972

(Figures 1, 2).

Holotype. AMNH FARB 6940. An almost complete skeleton preserved in part and counterpart blocks of cannel coal that lacks the skull anterior of the posterior orbital margin, the ventral portion of the shoulder girdle, and regions of the tail.

Locality, horizon, collector. Coal mine operated originally by the Ohio Diamond Coal Company at Linton, Saline Township, Jefferson County, Ohio, United States (see Hook and Baird, 1986, for details). Local cannel coal immediately below the Upper Freeport coal, Allegheny Group, Moscovian, Upper Carboniferous.

Revised differential diagnosis. A basal eureptile with the following unique combination of characters: thirty-one presacral vertebrae, neural arches anteroposteriorly elongated and hatchet-shaped, reduced phalangeal count of $2-2-3-4$ ? -3 in the manus and 2-2-3-4-3 in the pes, phalanges elongate, terminal phalanges thin and strongly hooked distally. Differs from diapsids based on the lack of temporal fenestration. Differs from Captorhinidae, but shares with Cephalerpeton and most "protorothyridids" the presence of abbreviated cheek and parietal regions. Further differs from Captorhinidae but shares with Cephalerpeton, Paleothyris, as well as most early diapsids the presence of elongated gracile limbs. Shares with 


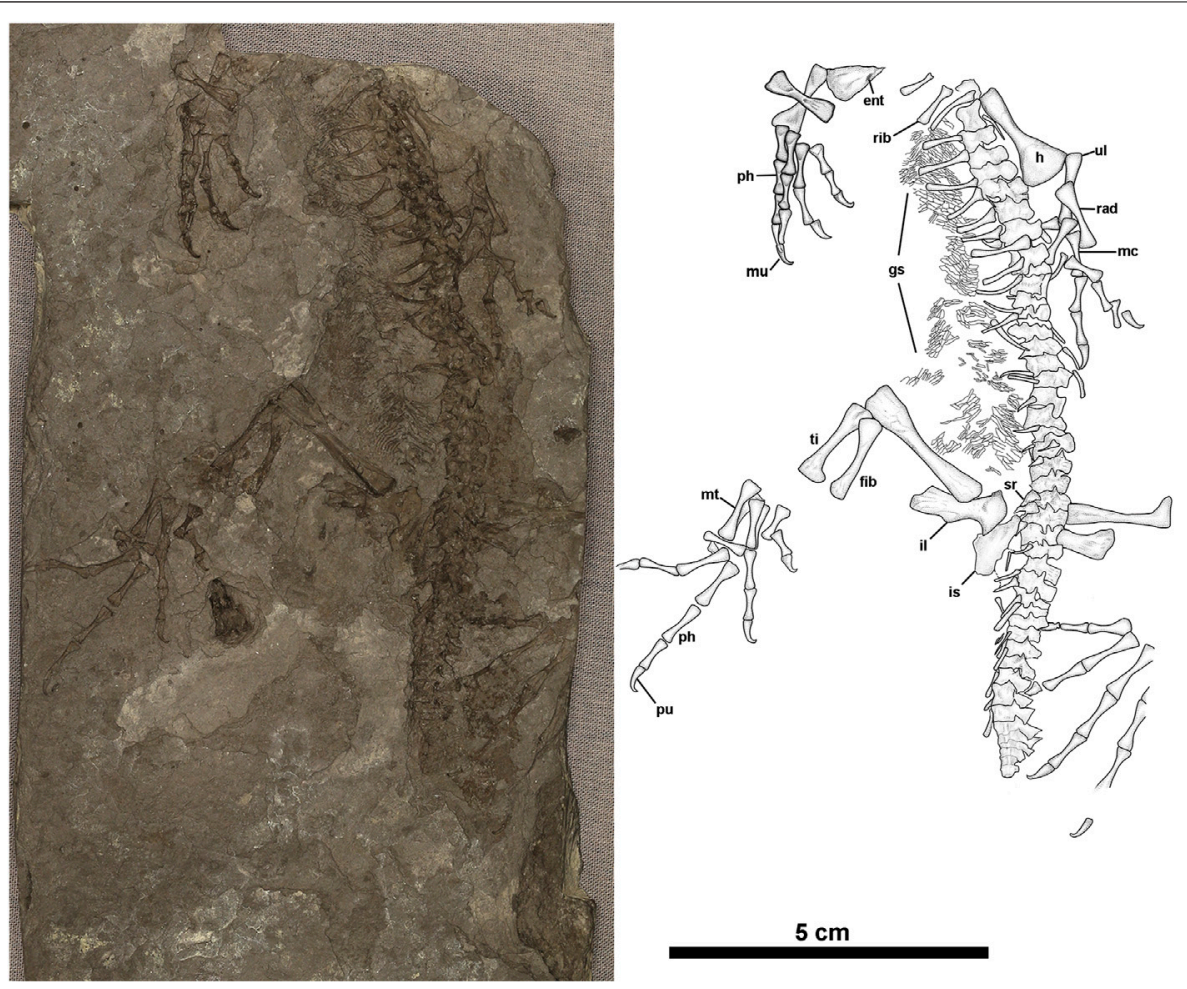

FIGURE 1 | Anthracodromeus longipes (CM 81532), (A) photograph and (B) illustration of CM 81532. Anatomical abbreviations: ent = entepicondylar foramen, $\mathrm{f}=$ femur, fib = fibula, $\mathrm{gs}=$ gastralia, $\mathrm{h}=$ humerus, is = ischium, il = ilium, $\mathrm{mc}=$ metacarpal, $\mathrm{mt}=$ metatarsal, $\mathrm{mu}=$ manual ungual, $\mathrm{ph}=\mathrm{phalanx}, \mathrm{pu}=\mathrm{pedal}$ ungual, $\mathrm{rad}=$ radius, $\mathrm{sr}=$ sacral ribs, ti-tibia, $\mathrm{ul}=$ ulna.

most early reptiles, except for Acleistorhinidae, the absence of strongly pitted cranial ornamentation.

Referred material. CM 25282 partial postcranial skeleton in counterparts and 81532 (Figure 1), a single part of an almost complete postcranial skeleton, missing the posterior portion of the tail, a few digits, and anteriormost cervical vertebrae. The skeleton is preserved in the right dorsolateral aspect.

Ontogenetic assessment. In the absence of cranial remains of CM 81532, the development of the axial and appendicular skeleton can be examined as an indicator of maturity. The lack of or weak ossification of long bone epiphyses and the development of neural spines can be reliable indicators of immaturity in squamates (Maisano, 2001; Maisano, 2002), and these indicators have often been informally applied to studies on early amniotes (e.g., Carroll and Baird, 1972; Botha-Brink and Modesto, 2009; Richards, 2016; Mann et al., 2019; Maddin et al., 2020). Considering these criteria, the three known specimens of Anthracodromeus can be regarded as skeletally immature and mature individuals. The holotype skeleton (AMNH FARB 6940) lacks both strong development of terminal articular facets and ossified carpal elements (although it is possible the latter could have been dissociated), but it does possess well-ossified, sculptured, tall, "hatchet-shaped" neural spines and a wellossified tarsus (Carroll and Baird, 1972). In comparison, the closely related and slightly larger "protorothyridid" Cephalerpeton lacks virtually all of the aforementioned features, which likely indicate an immature ontogenetic state of ossification (Carroll and Baird, 1972; Mann et al., 2019). Although of similar size to the holotype, CM 81532 is apparently more immature based upon the absence of any ossified carpals and tarsals, less well-ossified neural arches (described below), and the weakly ossified epiphyseal surfaces on stylopodial elements. Finally, the largest known and most skeletally mature specimen of Anthracodromeus (CM 25282) preserves portions of the pelvic and caudal regions; the femur, however, bears well-developed proximal and distal articular surfaces (Reisz and Baird, 1983). Additionally, the femur bears a more noticeable sinusoidal shape, which is a similar trend observed in ontogenetically mature varanopids (Maddin et al., 2020).

Comments. CM 81532 is referred to Anthracodromeus longipes based on the shared presence of hatchet-shaped neural spines and hyper-elongated phalanges that bear unguals with strong distal hooking. Carroll and Baird (1972) and later Reisz and Baird (1983) considered there to be a close relationship between Anthracodromeus longipes from Linton, and Cephalerpeton ventriarmatum from Mazon Creek, Illinois. Although Reisz and Baird (1983) convoluted the anatomy of Cephalerpeton with the recently recognised parareptile Carbonodraco lundi (Mann et al., 2019) from Linton, the similarities between the holotype specimens of Anthracodromeus and Cephalerpeton remain valid. The 
minimal posterior skull material preserved in Anthracodromeus, however, does not adequately compare with that of Cephalerpeton (Reisz and Baird, 1983). Furthermore, with differences in ontogenetic states between the two-Cephalerpeton being more immature yet larger-it is difficult to reconcile these two taxa as congeneric, and they should continue to remain distinct taxa.

\section{Comparative Osteology}

The holotype of Anthracodomeus (AMNH FARB 6940) consists of a fairly well-preserved skeleton missing only the anterior portion of the skull and mandible, as well as the distal part of the tail. Re-examination of the holotype did not find significant differences from the descriptions of Carroll and Baird (1972) or Reisz and Baird (1983). Unfortunately, the new skeleton, CM 81532 , does not preserve any portion of the skull or shoulder girdle-thus details of these regions remain unrecorded.

As noted above, CM 81532 includes most of the postcranial skeleton (Figure 1). Although vertebrae are preserved nearly articulated, the vertebrae are less well-preserved than those of the holotype, which is likely due to poor ossification. This is most noticeable in the presacral neural spines, which are slightly rounded on their margins, anteroposteriorly thinner, and generally less well developed in the mid-dorsal series of the vertebrae. Approximately 23 presacrals are preserved in lateral aspect and consist of fully formed centra with no ossified intercentra. They most likely represent presacrals $8-31$, based on the presence of a complete series of 31 presacrals in the holotype. The presence of hatchet-shaped, anteroposteriorly elongated neural spines is unique among most basal eureptiles and more closely resembles that of some early synapsids (Carroll and Baird, 1972; Reisz, 1972; Mann and Paterson, 2019; Mann and Reisz, 2020). In the better-preserved neural spines, the distinct "ball peened" sculpture that characterises the holotype is also present (Carroll and Baird, 1972). Reisz and Baird (1983) interpreted this feature as a possible result of immaturity, and its presence in the skeletally immature, CM 81532, supports this hypothesis. Two sacral vertebrae are present, based on the presence of two sacral ribs. The preserved tail consists of approximately 13 vertebrae whose fidelity of preservation diminishes distally, somewhat like that seen in the holotype specimen. Because the tail preserved on CM 81532 is abruptly truncated and weakly ossified at its terminus, this may indicate both caudal autotomy and the onset of regeneration, which is known to occur in other early reptile groups (e.g., Leblanc et al., 2018). If so, they are the oldest record of such an escape mechanism (autotomy) in the fossil record.

In general, the rib morphology of CM 81532 is similar to the holotypes of Anthracodromeus and Cephalerpeton (Carroll and Baird, 1972; Mann et al., 2019). They are gently curved cylinders of moderate to short length that bear the holocephalous morphology shared with many other early amniotes. There also is a slight expansion at their distal end.

CM 81532 preserves a partially articulated series of flattened, tube-shaped, gastralia. These gastralia are similar to those in the holotype of Anthracodromeus (Carroll and Baird, 1972) and in Cephalerpeton ventriarmatum (Mann et al., 2019), Both forelimbs are present, the left being more complete (Figures 2C,D). The right humerus is represented by a partial distal end that appears to reveal an entepicondylar foramen (Figure 1B). The left humerus is present but lacks development of processes and condyles at either end; it is expanded distally, perhaps more so than in the holotype. The diaphysis appears slightly thicker and more robust than that of the holotype, however this could be a result of limb orientation and crushing. The ulnae and radii are well-preserved in both limbs and appear to be less rod-like than those of the type, being noticeably bowed and expanded both distally and proximally. These elements are approximately subequal in size to each other and about half the length of the humerus.

The manus of CM 81532 is well preserved, though the carpus is apparently unossified. Additionally, only four digits are preserved on either side, the fifth digit on the right manus and the fourth digit on the left manus likely became dissociated post-mortem. The phalangeal count of the manus is 2-2-3-4?-3, which is reduced compared to the standard count of 2-3-4-5-3 in most early amniotes. The fourth digit is estimated to also have a reduced count of four, however, the terminal phalanx is not preserved in the right manus to confirm this. Re-inspection of the holotype reveals that neither the manus nor the pes preserve complete digits (see Supplementary Figures S1-S3). Therefore, the phalangeal counts presented by Carroll and Baird (1972) were likely estimated based on more complete PermoCarboniferous reptile material. The manual metacarpal lengths also present interesting patterns of $1<4<5<3<2$, with metacarpals two and three being significantly elongated (see Supplementary Table S10). Each phalanx decreases slightly in size distally but not by an appreciable amount. The morphology of the metacarpals and phalanges are elongate and slender, particularly in the midshaft of each element. The unguals of each digit are gracile and strongly recurved or hooked at the tip. The recurved morphology of the distal phalanx is most noticeable on the left manus, which is exposed in dorsolateral perspective.

The ossified pelvic girdle consists of the ilia preserved on either side of the vertebral column, and an ischium on the right side. The ilia are tall, approximately half the length of the femora. The length and shape of the ilia compare well to those of the holotype, but they bear even more resemblance to the referred specimen, CM 25282 (Carroll and Baird, 1972; Reisz and Baird, 1983). The proximal end of the right ilium is expanded slightly to form part of the acetabulum. The right ilium also bears lightly spaced, linear grooves toward the distal margins of the posteroventral process. The right ischium is poorly preserved but appears to be long and roughly sub-rectangular in shape. There are the possible remains of a pubis, between the ischium and vertebral column, however, these remains are too poorly preserved to identify with any confidence.

Both hind limbs are represented on CM 81532 with the right more completely represented. The femur shows a long cylindrical morphology that is more greatly expanded at the distal end than the proximal end. The epiphyses are generally poorly ossified, revealing the immaturity of the specimen as discussed above. The right tibia and fibula are two-thirds the length of the right femur. Both zeugopodial elements are gently bowed and opposed to one another. 


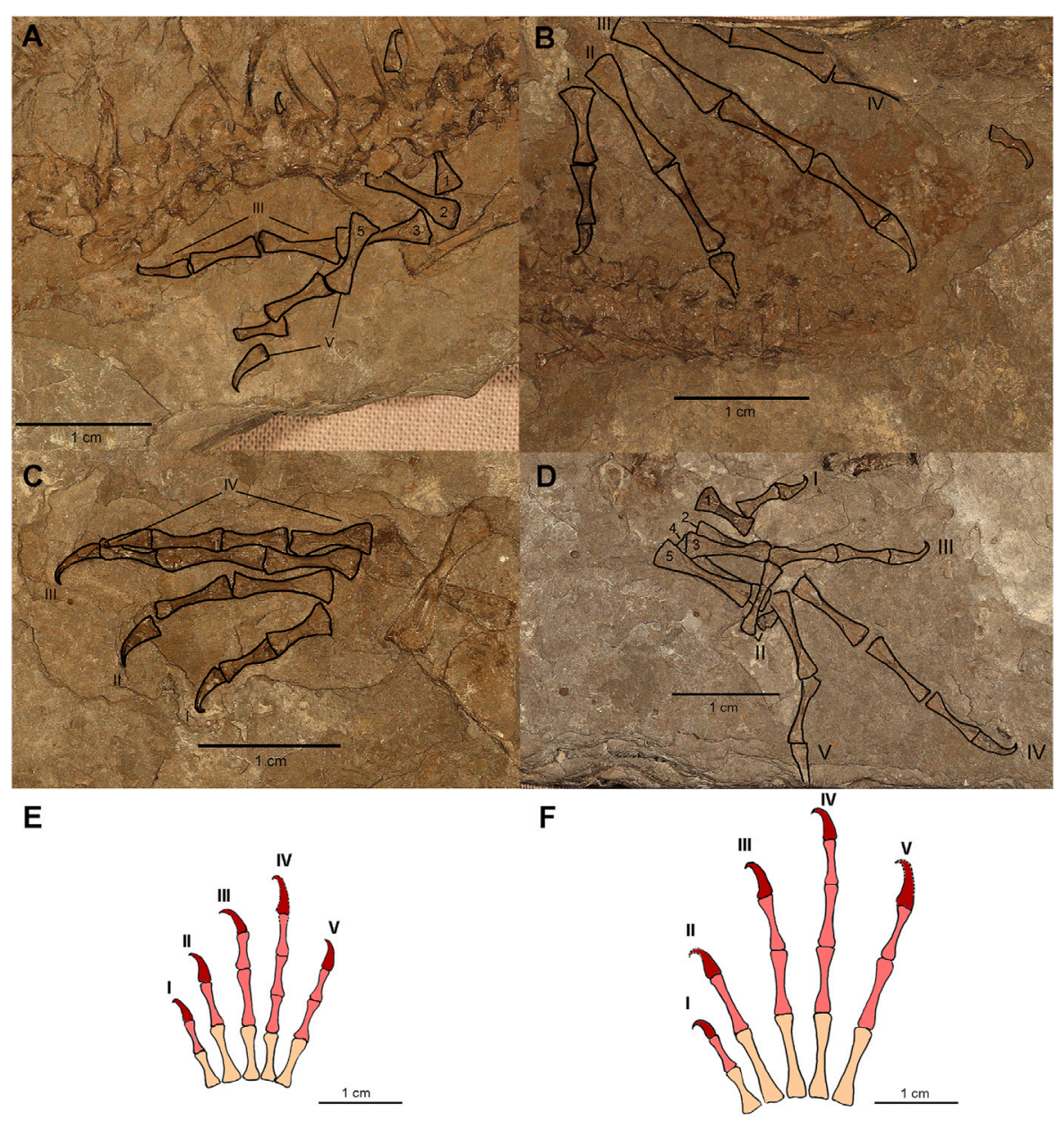

FIGURE 2 | Limbs of CM 81532. (A) Photograph of the left forelimb with manual elements outlined and labeled. (B) Photograph of the left hindlimb with pedal elements outlined and labeled. (C) Photograph of the right forelimb with manual elements outlined and labeled. (D) Photograph of the left hindlimb with manual elements outlined and labeled. (E) Reconstruction of the right manus. (F) Reconstruction of the right pes. Roman numerals in A-F identify digits while numbers 1-5 indicate metatarsal and metacarpal position. Phalangeal reconstructions based on the anatomy of AMNH FARB 6940 and CM 81532 . Colors on reconstructions indicate: metatarsals $/$ metacarpals $=$ peach, main series phalanges $=$ light red, terminal phalanges $=$ dark red.

The pedal anatomy is preserved on both sides of CM 81532 (Figure 1 and Figure 2A,B). No tarsal elements are preserved, which is unexpected given the presence of the astragalus and calcaneum in the holotype, although this may be from postmortem disarticulation. The left pes is completely missing digit $\mathrm{V}$, while the right pes, although slightly disarticulated, appears to have complete representation of the digits. Similar to the manus, the phalangeal formula appears to be reduced to 2-2-3-4-3; this is in contrast to the standard pes phalangeal formula of 2-3-4-5-4. The metatarsal length order is $1<2<3<5<4$, which is similar to other early reptiles (Carroll, 1969; Carroll and Baird, 1972) (see Supplementary Table S10). The metatarsals and phalanges are generally elongated with expanded ends and narrow shafts that serially decrease in length distally, as in the holotype. The pedal unguals are narrow, conical in cross-section, strongly recurved with a hooked apex. As in the manus, there is a slight constriction at the apex (distalmost region) of the ungual where the ventral curvature is greatest. Finally, in Anthracodromeus longipes the pes is the most remarkable structure, with both the metatarsals and phalanges being highly elongated compared to other known early reptiles. This character is possessed by the holotype (AMNH FARB 6940) and CM 81532 and is an autapomorphy of the genus (Carroll and Baird, 1972). In CM 81532, the pedes are proportionally as long as the stylopodial and zeugopodial regions of the same leg combined.

\section{Phalangeal Length Comparison}

To evaluate if Anthracodromeus was adapted for scansoriality through phalangeal elongation (Carroll and Baird, 1972; Spindler et al., 2018), we compared the manual proportions of this taxon with the extant and extinct taxa presented by Fröbisch and Reisz (2009). Within the ternary plot, Anthracodromeus plots with the extant taxa, and it is most comparable to the arboreal marsupials, primates, and chamaeleonids (Figure 3; see Fröbisch and Reisz 2009 for a breakdown of the ecological group). We found that Anthracodromeus is largely similar to some extant arboreal taxa, 


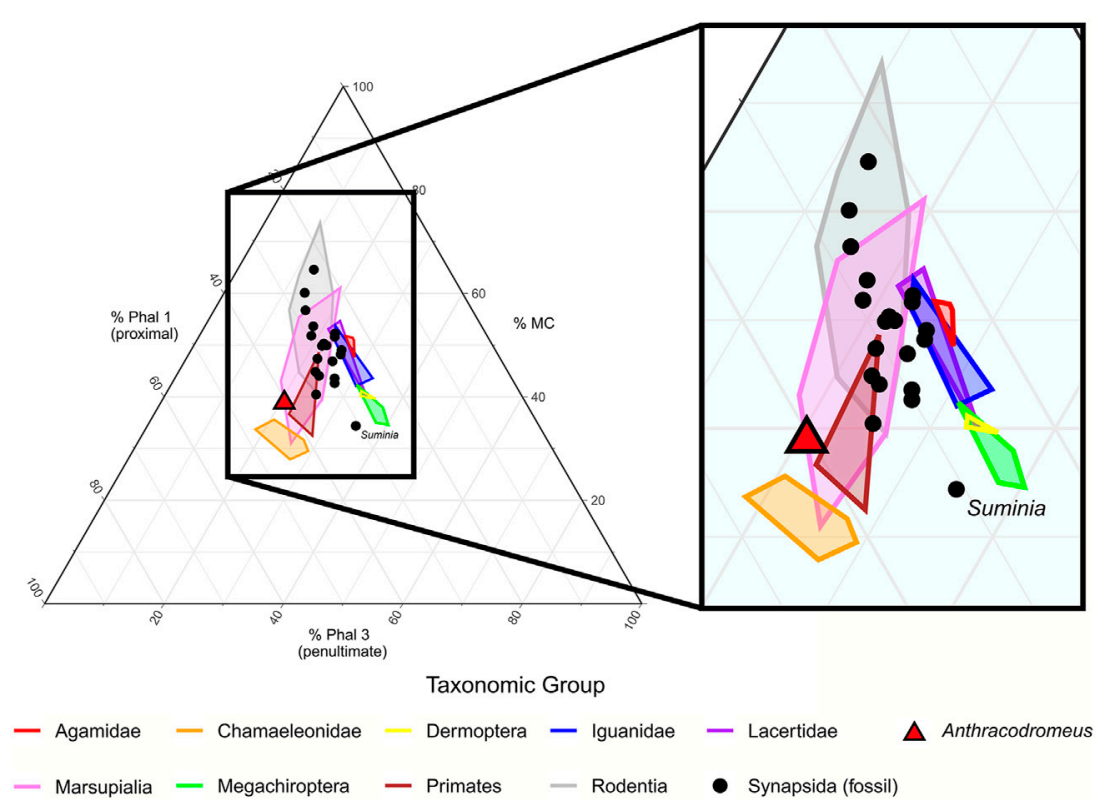

FIGURE 3 | Ternary plot of the manual phalangeal proportions of digit III of Anthracodromeus and the extant and extinct comparative taxa from Fröbisch and Reisz (2009). Lines represent convex hulls of the different taxonomic groups. MC, metacarpal; Phal 1, phalanx 1; Phal 3 , phalanx 3.

and has proportionately longer proximal phalanges and a shorter metacarpal than the extinct terrestrial taxa included by Fröbisch and Reisz (2009), although the difference is not as distinct as Suminia. This suggests that if Anthracodromeus was scansorial, it was not using the pronounced penultimate phalangeal elongation strategy employed by the synapsid Suminia. Instead, the manus itself had become extremely elongated, while proportions of the bones remained overall similar to other non-scansorial amniotes, though the proportions of the proximal phalanges had increased slightly.

\section{Ungual Curvature Comparison}

To further assess climbing capability of the uniquely recurved unguals of Anthracodromeus, we used a modified comparative dataset of Birn-Jeffery et al. (2012), and compared ungual curvature of both living amniotes and extinct PermoCarboniferous amniotes. We found that the outer curvature of Anthracodromeus is comparable to that of the perching taxa, but it also overlaps with the ground dwelling taxa (Figure 4A). This is unsurprising, considering that Birn-Jeffery et al. (2012) reported that there was considerable overlap between the ecological groups. However, it is interesting to note that the outer ungual curvature of Anthracodromeus is more extreme than that of all other extinct taxa included (that do not plot clearly with extant groups), except for Haptodus and Ascendonanus. This suggests that the outer ungual curvature of Anthracodromeus is more consistent with climbing, perching, and predatory capabilities than most other contemporaneous species.

A different trend is apparent when comparing inner claw curvature against relative claw thickness (Figure 4B), which is slightly better at separating the ecological groups. Anthracodromeus still plots in between the perching group and the ground dwelling group, but many of the other extinct taxa also plot nearby Anthracodromeus. The only extinct taxon that clearly plots away from the terrestrial group is Ascendonanus, supporting past interpretations that this taxon was arboreal (Spindler et al., 2018). This trend is further evidenced when plotting inner claw curvature against outer claw curvature (Figure 4C). The four ecological groups are not distinctly separated from one another, but instead create a gradient of claw shapes from lower curvature at the bottom left (grounddwelling) to greater curvature at the top right (predatory). In this plot, the unguals of Anthracodromeus, Haptodus, and Ascendonanus plot further toward the upper right than any of the other extinct taxa, the rest of which clearly plot with the ground-dwelling group. Overall, the relatively strong curvature of the unguals of Anthracodromeus suggests that they were likely better capable of clinging than most other coeval amniotes, although the similarity between Anthracodromeus and the terrestrial taxa suggests that scansoriality was probably not the primary mode of locomotion.

\section{Ungual Morphometric Analysis}

To discern possible ungual functionality of Anthracodromeus we compared its shape and proportions to the keratinous claws of a large number of extant taxa using the recent dataset and methods of Thomson and Motani (2021). The principal component analysis (PCA) of claw shape produced 10 PC axes, but only axes one through three will be discussed here because they represent the greatest axes of significant shape variation (cumulative variation $=79.06 \%$; Supplementary Table S8). PC1 represents the greatest proportion of the variation (46.14\%) and is mostly driven by the shape and proportions of the claw with more positive PC1 scores representing overall 


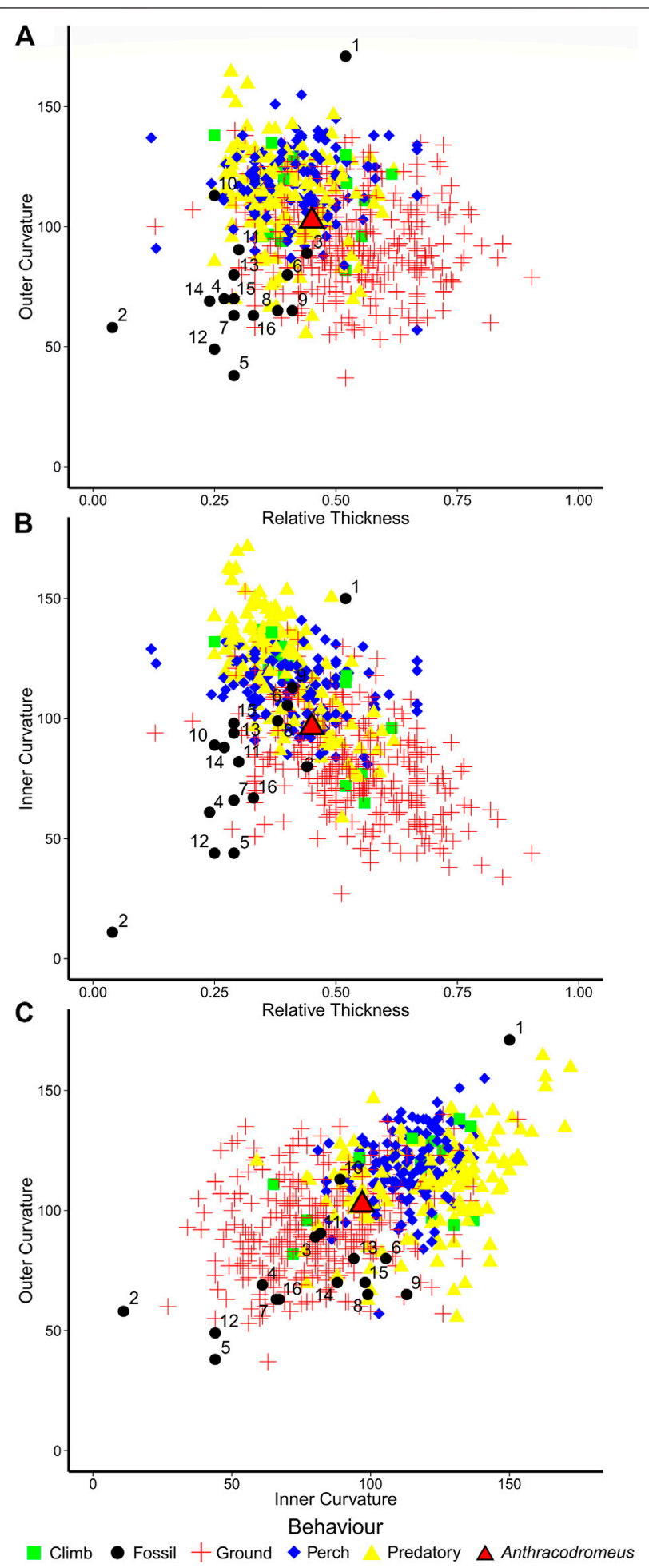

FIGURE 4 | Scatterplots of claw curvature and thickness from Birn-Jeffery et al. (2012) showing placement of Anthracodromeus and other coeval amniotes. (A) outer claw curvature vs. relative claw thickness, (B) inner claw curvature vs. relative claw thickness, and (C) outer claw curvature vs. inner claw curvature. Taxa: 1, Ascendonanus nesterli; 2, Batropetes fritschi; 3, Cabarzia trostheidei; 4, Captorhinus aguti; 5, Cotylorhynchus romeri; 6, Dimetrodon limbatus; 7, Edaphosaurus boanerges; 8, Eocasea martini; 9, Erpetonyx arsenaultorum; 10, Haptodus garnettensis; 11, Martensius bromackerensis; 12, Mesenosaurus romeri; 13, Palaeohatteria longicaudata; 14, Spinoaequalis schultzei; 15, Suminia getmanovi; 16, Varanops sp. 


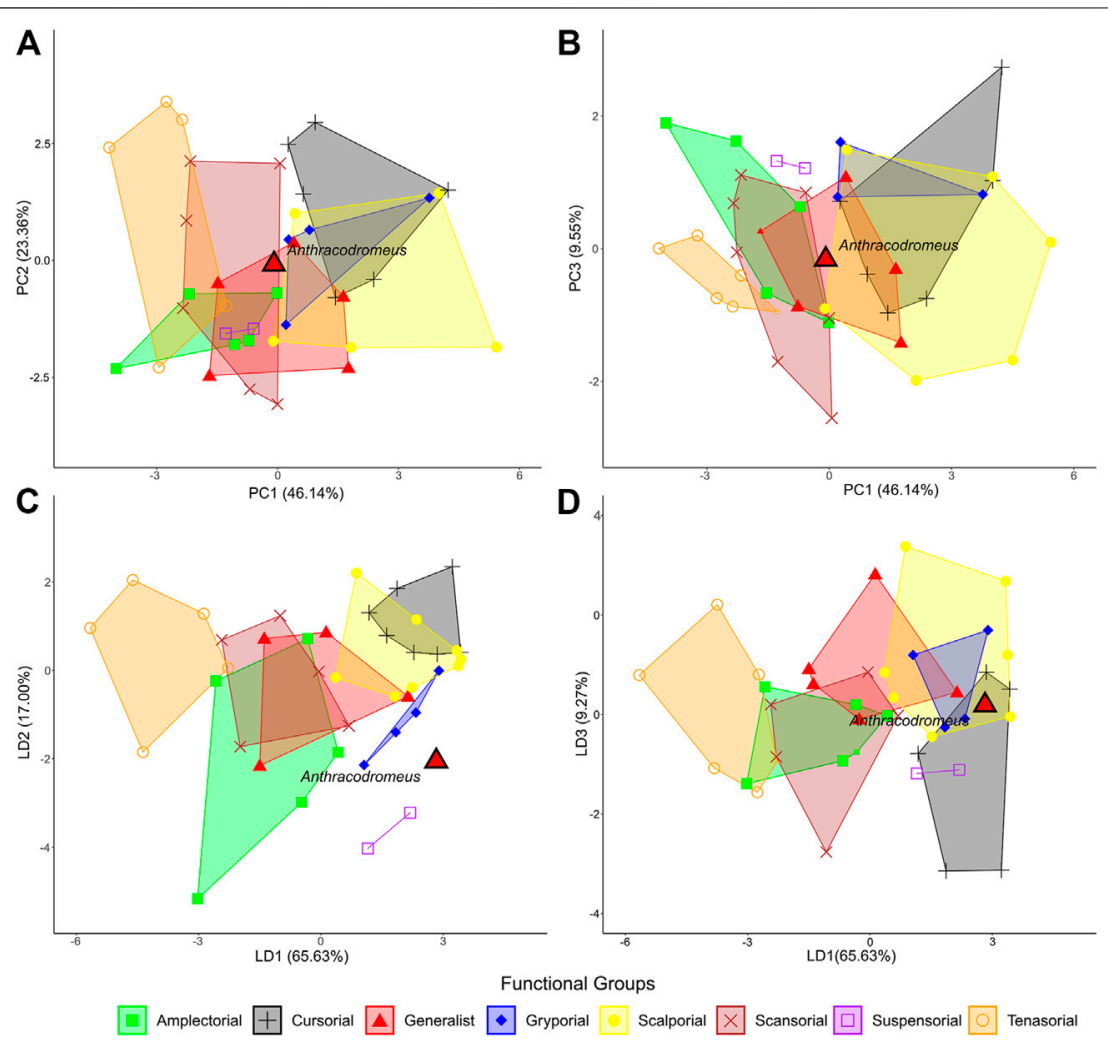

FIGURE 5 | Comparison of claw shape in Anthracodromeus to those of the extant amniotes from thompson and motani (2021). Visualizations of the main PC axes: (A) PC1 vs. PC2 (69.50\% of the variation); (B) PC1 vs. PC3 (55.69\% of the variation); and the main LD axes: (C) LD1 vs. LD2 (82.63\% of the variation); (D) LD1 vs. LD3 (74.90\% of the variation).

longer and thinner claws with a greater radius of curvature (Figure 5A) and PC1 negative scores representing shorter and thicker claws with a smaller radius of curvature. PC2 is mostly driven by the flexor tubercle and the ventral radius (23.36\%), where more positive PC2 scores represent claws with a thicker base depth and flexor depth and a smaller ventral radius (Figure 5A) and PC2 negative represent claws with a thinner base depth and flexor tubercle and a larger ventral radius. PC3 mostly represents the articular height and extension and the ventral curve length (9.55\%), where more positive PC3 scores represent claws with a greater articular height and smaller articular extension and ventral curve length and more negative PC3 score represent claws with a smaller articular height and greater articular extension and ventral curve length (Figure 5B). Even though they used raw measurements and we used size corrected residuals, the functional groups mostly overlap in PCA morphospace, which is largely similar to the results of Thomson and Motani (2021). Along PC1, Anthracodromeus overlaps with the scansorial, generalist, amplectorial, and scalporial groups; along PC2, Anthracodromeus overlaps all groups except for suspensorial and amplectorial; and along PC3, Anthracodromeus overlaps with all groups except for suspensorial and gryporial.

The linear discriminant analysis (LDA) produced seven LD axes, but only axes one through three will be discussed here since they represent the greatest axes of variation (cumulative variation
$=91.90 \%)$. LD1 (65.63\%) mainly represents dorsal arc length and the prominence of the flexor tubercle, where LD1 positive values represent claws with shorter dorsal arcs and shallower flexor tubercles relative to their base depth and LD2 negative values represent claws with larger dorsal arcs and deeper flexor tubercles relative to their base depth (Figure 5C). LD2 (17.00\%) represents the ventral curvature of the claws, articular extension, and dorsal arc length, where LD2 positive values represent smaller ventral curve lengths and greater articular extensions and dorsal arc lengths, and LD2 negative values represent larger ventral curve lengths and smaller articular extensions and dorsal arc lengths (Figure 5C). LD3 (9.27\%) represents the flexor tubercle and claw length, where $\mathrm{LD} 3$ positive values represent a large flexor tubercle relative to base depth and a shorter dorsal arc length, and LD3 negative values represent a small flexor tubercle relative to base depth and larger dorsal arc length. The groups are best separated from one another along LD1, with little separation along the other LD axes. Along LD1, Anthracodromeus overlaps with the cursorial, scalporial, and gryporial groups, and along LD2, Anthracodromeus plots with the generalist, cursorial, amplectorial, and gryporal groups. Along LD3, Anthracodromeus overlaps with all groups except suspensorial.

Overall, the LDA is much better at separating the functional groups than the PCA. The classification accuracy of LDA with the 11 linear variables corrected for size and phylogeny was still high 
TABLE 1 | Posterior probabilities for the assignment of Anthracodromeus to the eight functional groups.

\begin{tabular}{|c|c|c|c|c|c|c|c|}
\hline Amplectorial & Cursorial & Generalist & Gryporial & Scalporial & Scansorial & Suspensorial & Tenasorial \\
\hline$<0.0001$ & $<0.0001$ & 0.0001 & 0.0698 & 0.0004 & $<0.0001$ & 0.9295 & $<0.0001$ \\
\hline
\end{tabular}

(74.32\%), slightly lower than that of the full linear dataset from Thomson and Motani $(2021 ; 81.25 \%)$. This suggests that the removal of the cross-section data only slightly weakens the predictive accuracy of these data. Posterior probabilities indicate that the ungual of Anthracodromeus is most similar to the suspensorial group (92.95\%), with gryporial being the second most similar groups (6.98\%; Table 1).

\section{DISCUSSION}

In what were brief paleoecological comments, Carroll and Baird (1972) noted anatomical features of Anthracodromeus that they regarded as arboreal adaptations. These included elongated limb elements, where the stylopodium and zeugopodium have similar lengths, unlike the limbs of other known basal amniotes. They also noted that, compared to other early reptiles and early amniotes in general, Anthracodromeus had uniquely long manus and pedes. More recently, roughly comparable morphologies have been described in varanopids (Archaeovenator hamiltonensis Reisz and Dilkes, 2003; Ascendonanus nestleri Spindler et al., 2018). Anthracodromeus demonstrates a similar marked elongation of both the metatarsals and phalanges. Unlike the early arboreal therapsid Suminia (Fröbisch and Reisz, 2009), which has penultimate phalanx elongation as a mode of digit elongation, Anthracodromeus achieved its manual and pedal length simply by elongating each digital element, primarily the proximal phalanx, while oddly enough also reducing the number of phalanges in the manus and pedes. Spindler et al. (2018), in a discussion on arboreality in early amniotes, speculated that Anthracodromeus was scansorial and possibly used a unique form of phalangeal grasping. The latter interpretation, however, was based upon the poorly preserved unguals of the holotype and an incorrect identification of the number of phalanges in both the manus and pes.

The new skeleton described here provides the most complete record of the terminal phalanges in Anthracodromeus and closely matches the complete singular manual and pedal unguals of the holotype (Figures 1, 2). The unguals on CM 81532 (Figure 2) are highly curved with strong ventral "hooking" terminally. This curved morphology is observed in the claws of a number of extant reptiles with scansorial and arboreal habits (Zani, 2000; D'Amore et al., 2018). It is hypothesized that the unguals (and therefore claws) of Anthracodromeus were likely used for climbing and clinging to surfaces. This would indicate an earlier experiment with climbing niches in terrestrial vertebrate ecosystems than is currently recognised, appearing as early as the Moscovian (late Carboniferous). Prior to this study, the earliest record of scansoriality in tetrapods was the Early Permian varanopid Ascendonanus nesterli (Spindler et al., 2018). The most compelling early record of a specialized climber remains the Late Permian therapsid Suminia getmanovi (Fröbisch and Reisz, 2009).

Comparisons of the manual proportions of Anthracodromeus with the extant and extinct taxa of Fröbisch and Reisz (2009) demonstrate that although Anthracodromeus has slightly elongated manual proportions that are consistent with some arboreal groups (e.g., primates), this elongation is due to slight proportional lengthening of the proximal phalanx, and it does not exhibit the prominent elongation observed in Suminia (Figure 3). This suggests that although Anthracodromeus has greatly enlarged manus and pedes, it likely did not rely on phalangeal grasping as has been proposed previously (Spindler et al., 2018), though the large surface area of the manus and pedes may have facilitated clinging through increased traction to some degree. It is noteworthy that the ternary plot shows extant taxa plotting in two distinct clumps, one consisting primarily of reptiles with longer penultimate phalanges, and a second consisting of primarily mammals with longer proximal phalanges (Figure 3). This separation of the two taxonomic groups may be due to differences in phalangeal counts, where mammals tend to have a lower count (e.g. 2-3-3-3-3) compared to reptiles (e.g. 2-3-4-5-3). This could also explain why Anthracodromeus is plotting with extant mammals, given that it too exhibits a lowered phalangeal count.

It has long been suggested that the ancestral amniote phalangeal formulae are 2-3-4-5-3 for the manus and 2-3-45-4 for the pes (Romer, 1956; Carroll, 1988; Fedak and Hall, 2004). Reassessment of the manus and pes of the early reptile Anthracodromeus longipes reveals hypophalangy or reduced phalangeal counts of 2-2-3-4?-3 and 2-2-3-4-3, respectively. Because Anthracodromeus appears within the earliest stages of amniote evolution this variation is unexpected and demonstrates an unrecognised ecomorphological diversity in the autopodium of early reptiles. Variation in phalangeal counts and digit morphology can arise from adaptive evolution to new ecological niches including aquatic, fossorial, scansorial, and cursorial habits, but also disruptions to limb development (Romer, 1956; Shapiro et al., 2007). In Anthracodromeus, a lack of any common aquatic or fossorial anatomical specializations makes these lifestyles unlikely candidates for explaining the hypophalangy observed in the manus and pes (Gans, 1975; Greer, 1987; Greer, 1991; Fedak and Hall, 2004; Camaiti et al., 2021). We find the most likely explanation for the combination of features found in the manus and pes of Anthracodromeus is that they are adaptations for scansoriality. Unlike living 
fossorial lizards (Camaiti et al., 2021), the reduced phalangeal counts of Anthracodromeus contrast the proportional elongation of phalanges in the manus and pes, which accounts for their formidable length. Hypophalangy in Anthracodromeus reduced the number of joints in the affected fingers and toes and consequently likely reduced the flexibility of the elongated digits, which may have provided further stability while clinging to surfaces and climbing over terrain. Perhaps the most ecologically comparable living reptiles to Anthracodromeus are scansorial-capable agamid lizards that share similar suites of skeletal features sometimes including phalangeal losses (Greer 1991).

Comparisons of the ungual curvature of Anthracodromeus with the claws of extant amniotes (Birn-Jeffrey et al., 2012) demonstrates that its ungual exhibits curvature more consistent with scansorial habits, though there is also considerable overlap with terrestrial taxa (Figure 4). Interestingly, Anthracodromeus possesses unguals that are more strongly curved than most other coeval amniotes (Figure 4, black dots), suggesting that Anthracodromeus was more capable of clinging than other Permo-Carboniferous amniotes. Perhaps the only exception is Ascendonanus nesterli that possesses highly curved unguals that were likely adapted for arboreality as suggested by Spindler et al. (2018). The overlap of Anthracodromeus with terrestrial taxa may be due to the unusual shape of the unguals of this taxon, where they are strongly curved only at the distal-most tip and fairly straight along their length (Figure 2).

When evaluating ungual functionality, Anthracodromeus plots to the far right of the LDA, though well outside of the morphospace of the extant groups, further suggesting that the shape of the unguals of Anthracodromeus is unusual. Although the PCA demonstrated that the length, depth, and overall curvature of the unguals of this taxon are most similar to the generalist and scansorial taxa (Figures 4A,B), the LDA suggests that the dorsal arc length and flexor tubercle are small in proportion to its long dorsal curve length, a combination of traits most similar to the elongated keratinous claws of sloths, and some fossorial and cursorial taxa (Figures 4C,D). However, most of the taxa in this dataset have a claw curvature that is fairly consistent along their lengths. Anthracodromeus, in contrast, has long unguals that are strongly hooked only at the distal-most end, and this distalmost hooking is likely not being captured by the linear measurements in this dataset. Furthermore, the keratinous claw almost certainly extended past the tip of the ungual, possibly making its curvature more consistent with, and therefore its shape more similar to, other more strongly curved claws.

A major caveat of these ungual analyses that must be considered is the issue of comparing bony unguals to keratinous claws. Although some studies have found that the curvature of the sheath is mostly similar to the curvature of the ungual (Hedrick et al., 2019) and can be used to accurately estimate their function (Cobb and Sellers, 2020), these studies only tested the similarities between ungual and claw curvature in birds. Therefore, the reliability of ungual shape in correctly reflecting the shape of the keratinous claw in a more complex morphometric analysis at a wider phylogenetic scale is unknown.

The unusual combination of ungual traits, and differences between the ungual and claw morphology, are likely why the LDA classified Anthracodromeus in an unexpected way. The assignment of Anthracodromeus to the suspensorial group (arboreality via hanging) is surprising given how few taxa exhibit this form of locomotion, but this reflects the overall proportions of the ungual (i.e., long and thin), and does not capture the strong distal hooking of Anthracodromeus. Of course, claws do not have a single function, and they are capable of performing multiple functions to facilitate locomotion over different materials. The results of the functional comparison show that this is likely true for Anthracodromeus, since the LDA demonstrated that it was not hyper-adapted for scansoriality, though the relative length and depth of the unguals (PC1 and PC2) are similar to generalist and scansorial taxa and therefore may have aided in clinging as one of many functions.

Cumulatively, our data indicate that Anthracodromeus did not rely on penultimate phalangeal elongation to facilitate scansoriality via grasping, as reported in Suminia (Fröbisch and Reisz, 2009), but instead may have relied primarily on distal curvature of the unguals to cling to surfaces. The enlarged manus and pedes of Anthracodromeus would have assisted with clinging to some degree through increased surface area and traction. Therefore, we hypothesize that the unguals of Anthracodromeus may have aided in clinging, a potentially useful adaptation for a taxon living among the stumps, logs, and lycopsid trees of the Carboniferous coal swamps (Falcon-Lang, 2003; Falcon-Lang et al., 2006). Adaptations that facilitated clinging in Anthracodromeus demonstrates that climbing behavior likely arose in the Carboniferous, rapidly after the origin of amniotes, and well before such behavior developed in the synapsid lineage. Climbing adaptations in early amniotes would have provided a number of ecological advantages, including the ability to escape large predators and to access novel food sources. Furthermore, this suggests that the Pennsylvannian adaptive radiation of amniotes saw higher levels of ecomorphological diversity than previously recognised, with amniotes exploiting a variety of novel terrestrial niches.

\section{CONCLUSIONS}

Anthracodromeus longipes, an early eureptile from the classic late Carboniferous locality of Linton, Ohio, was known previously from only two specimens. A third specimen recovered in recent years from Linton provides new anatomical insights, most notably the presence of hypophalangy and manual and pedal unguals that are distinctly hooked. Comparative anatomical and morphometric analyses suggest that the unguals of Anthracodromeus likely facilitated clinging to surfaces, thereby supporting some degree of scansorial locomotion. Although the manual and pedal phalangeal proportions of Anthracodromeus are elongated, they do not indicate an exclusively arboreal habit. While these ecological inferences are based on comparisons to 
living tetrapods that are adapted for modern environments, it is possible that Anthracodromeus was uniquely specialised for climbing in Carboniferous paleoenvironments that were dominated by large lycopsid trees. Overall, a re-evaluation of the anatomy of Anthracodromeus suggests that early reptiles experimented with various levels of scansoriality as early as the mid-Pennsylvannian, not long after amniotes first appeared in the fossil record.

\section{DATA AVAILABILITY STATEMENT}

The original contributions presented in the study are included in the article/Supplementary Material, further inquiries can be directed to the corresponding author.

\section{AUTHOR CONTRIBUTIONS}

AM and TWD conceived the study. AM, TWD, and ACH analyzed the data. SEP assisted with morphometric analyses. $\mathrm{AM}, \mathrm{TWD}$, and $\mathrm{ACH}$ made the figures. AM, TWD, $\mathrm{ACH}$, $\mathrm{DSB}$, and SEP wrote and edited the manuscript.

\section{REFERENCES}

Berman, D. S., Maddin, H. C., Henrici, A. C., Sumida, S. S., Scott, D., and Reisz, R. R. (2020). New Primitive Caseid (Synapsida, Caseasauria) from the Early Permian of Germany. Ann. Carnegie Mus. 86 (1), 43-75.

Birn-Jeffery, A. V., Miller, C. E., Naish, D., Rayfield, E. J., and Hone, D. W. E. (2012). Pedal Claw Curvature in Birds, Lizards and Mesozoic Dinosaurs Complicated Categories and Compensating for Mass-specific and Phylogenetic Control. PLoS ONE 7 (12), e50555. doi:10.1371/journal. pone.0050555

Botha-Brink, J., and Modesto, S. P. (2009). Anatomy and Relationships of the Middle Permian Varanopid Heleosaurus Scholtzi Based on a Social Aggregation from the Karoo Basin of South Africa. J. Vertebr. Paleontol. 29 (2), 389-400.

Camaiti, M., Evans, A. R., Hipsley, C. A., and Chapple, D. G. (2021). A Farewell to Arms and Legs: A Review of Limb Reduction in Squamates. Biol. Rev. 96 (3), 1035-1050. doi:10.1111/brv.12690

Carroll, R. L. (1969). A Middle Pennsylvanian Captorhinomorph, and the Interrelationships of Primitive Reptiles. J. Paleontol. 43 (1), 151-170.

Carroll, R. L., and Baird, D. (1972). Carboniferous Stem-Reptiles of the Family Romeriidae, Bull. Mus. Comp. Zoolog., 143. 321-363.

Carroll, R. L. (1964). "Early Evolution of the Dissorophid Amphibians," in Bulletin of the Museum of Comparative Zoology (Harvard University), 131, 161-250.

Carroll, R. L. (1988). Vertebrate Palaeontology and Evolution. New York: W. H. Freeman.

Cobb, S. E., and Sellers, W. I. (2020). Inferring Lifestyle for Aves and Theropoda: A Model Based on Curvatures of Extant Avian Ungual Bones. PLoS ONE 15 (2), e0211173. doi:10.1371/journal.pone.0211173

Core Team (2019). R: A Language and Environment for Statistical Computing. Vienna, Austria: R Foundation for Statistical Computing. Avabilable at: Fontanarrosa https://www.R-project.org/ (Accessed February 01, 2021).

D'Amore, D. C., Clulow, S., Doody, J. S., Rhind, D., and McHenry, C. R. (2018). Claw Morphometrics in Monitor Lizards: Variable Substrate and Habitat Use Correlate to Shape Diversity within a Predator Guild. Ecol. Evol. 8: 6766-6778. doi:10.1002/ece 3.4185

deBraga, M., and Reisz, R. R. (1995). A New Diapsid Reptile from the Uppermost Carboniferous (Stephanian) of Kansas. Palaeontology 38, 199-212.

Fedak, T. J., and Hall, B. K. (2004). Perspectives on Hyperphalangy: Patterns and Processes. J. Anat. 204 (3), 151-163. doi:10.1111/j.0021-8782.2004.00278.x

\section{ACKNOWLEDGMENTS}

We are indebted to Emily J. McDaniel for her help with illustrations of CM 81532. We thank Diane Scott and Robert R. Reisz (University of Toronto), who allowed access to fossil material from Oklahoma and Texas on loan to them. Ami S. Calthorpe, Bryan M. Gee, Sean P. Modesto, and Jason D. Pardo provided stimulating discussions. The late Donald Baird was the first to identify CM 81532 correctly, and he prepared much of the material used in this study. Robert W. Hook improved an early draft of the manuscript. Lastly but certainly not least, we thank Scott C. McKenzie for his generous donation of specimens from Linton to the Carnegie Museum of Natural History. The work was supported by and published though funds made available to SEP by Harvard University.

\section{SUPPLEMENTARY MATERIAL}

The Supplementary Material for this article can be found online at: https://www.frontiersin.org/articles/10.3389/feart.2021.675337/ full\#supplementary-material

Feduccia, A. (1993). Evidence from Claw Geometry Indicating Arboreal Habits of Archaeopteryx. Science 259 (5096), 790-793. doi:10.1126/science.259.5096.790 Falcon-Lang, H. J. (2003). Late Carboniferous Tropical Dryland Vegetation in an Alluvial-Plain Setting, Joggins, Nova Scotia, Canada. Palaios 18 (3), 197-211.

Falcon-Lang, H. J., Benton, M. J, Braddy, S. J., and Davies, S. J. (2006). The Pennsylvanian Tropical Biome Reconstructed from the Joggins Formation of Nova Scotia, Canada. J. Geol. Soc. 163 (3), 561-576.

Fischer, M. S., Krause, C., and Lilje, K. E. (2010). Evolution of Chameleon Locomotion, or How to Become Arboreal as a Reptile. Zoology 113 (2), 67-74. doi:10.1016/j.zool.2009.07.001

Ford, D. P., and Benson, R. B. J. (2020). The Phylogeny of Early Amniotes and the Affinities of Parareptilia and Varanopidae. Nat. Ecol. Evol. 4 (1), 57-65. doi:10. 1038/s41559-019-1047-3

Fröbisch, J., and Reisz, R. R. (2009). The Late Permian Herbivore Suminia and the Early Evolution of Arboreality in Terrestrial Vertebrate Ecosystems. Proc. R. Soc. B. 276, 3611-3618. doi:10.1098/rspb.2009.0911

Gans, C. (1975). Tetrapod Limblessness: Evolution and Functional Corollaries. Am. Zool 15 (2), 455-467. doi:10.1093/icb/15.2.455

Greer, A. E. (1991). Limb Reduction in Squamates: Identification of the Lineages and Discussion of the Trends. J. Herpetology 25, 166-173. doi: $10.2307 / 1564644$

Greer, A. E. (1987). Limb Reduction in the Lizard Genus Lerista. 1. Variation in the Number of Phalanges and Presacral Vertebrae. J. Herpetology 21, 267-276. doi: $10.2307 / 1563968$

Hamilton, N. E., and Ferry, M. (2018). Ggtern: Ternary Diagrams Using Ggplot2. J. Stat. Softw. Code Snippets 87 (3), 1-17. doi:10.18637/jss.v087.c03

Haeckel, E. (1866). Generelle Morphologie der Organismen. Allgemeine Grundz£uge der Organischen Formen-Wissenschaft, Mechanisch Begr£undet Durch Die Von C. Darwin Reformirte Descendenz-Theorie, etc, Volume 2. Berlin, Germany: . G. Reimer, 574

Hedrick, B. P., Cordero, S. A., Zanno, L. E., Noto, C., and Dodson, P. (2019). Quantifying Shape and Ecology in Avian Pedal Claws: The Relationship between the Bony Core and Keratinous Sheath. Ecol. Evol. 9, 11545-11556. doi:10.1002/ece3.5507

Holmes, R. B. (2003). The Hind Limb of Captorhinus Aguti and the Step Cycle of Basal Amniotes. Can. J. Earth Sci. 40 (4), 515-526.

Hook, R. W., and Baird, D. (1986). The Diamond Coal Mine of Linton, Ohio, and its Pennsylvanian-Age Vertebrates. J. Vertebr. Paleontol. 6 (2), 174-190. doi:10. 1080/02724634.1986.10011609 
LeBlanc, A. R. H., MacDougall, M. J., Haridy, Y., Scott, D., and Reisz, R. R. (2018). Caudal Autotomy as Anti-predatory Behaviour in Palaeozoic Reptiles. Scientific Rep. 8, 3328. doi:10.1038/s41598-018-21526-3

Maddin, H. C., Mann, A., and Hebert, B. (2020). Varanopid from the Carboniferous of Nova Scotia Reveals Evidence of Parental Care in Amniotes. Nat. Ecol. Evol. 4 (1), 50-56. doi:10.1038/s41559-019-1030-Z

Maddin, H. C., and Reisz, R. R. (2007). The Morphology of the Terminal Phalanges in Permo-Carboniferous Synapsids: an Evolutionary Perspective. Can. J. Earth Sci. 44 (2), 267-274. doi:10.1139/e06-076

Maisano, J. A. (2001). A Survey of State of Ossification in Neonatal Squamates. Herpetological Monogr. 15, 135-157. doi:10.2307/1467041

Maisano, J. A. (2002). Terminal Fusions of Skeletal Elements as Indicators of Maturity in Squamates. J. Vertebr. Paleontol. 22 (2), 268-275. doi:10.1671/ 0272-4634(2002)022[0268:tfosea]2.0.co;2

Mann, A., McDaniel, E. J., McColville, E. R., and Maddin, H. C. (2019). Carbonodraco lundi gen et sp. nov., the oldest parareptile, from Linton, Ohio, and new insights into the early radiation of reptiles, R. Soc. Open Sci., 6. 191191. doi:10.1098/rsos.191191

Mann, A., and Paterson, R. S. (2019). Cranial Osteology and Systematics of the Enigmatic Early 'sail-Backed' Synapsid Echinerpeton Intermedium Reisz, 1972, and a Review of the Earliest 'pelycosaurs'. J. Syst. Palaeontology 18 (6), 529-539. doi:10.1080/14772019.2019.1648323

Mann, A., and Reisz, R. R. (2020). Antiquity of "Sail-Backed" Neural Spine HyperElongation in Mammal Forerunners. Front. Earth Sci. 8, 83. doi:10.3389/feart. 2020.00083

Modesto, S. P., Scott, D. M., MacDougall, M. J., Sues, H.-D., Evans, D. C., and Reisz, R. R. (2015). The Oldest Parareptile and the Early Diversification of Reptiles. Proc. R. Soc. B. 282, 20141912. doi:10.1098/rspb.2014.1912

Olson, E. C. (1947). The Family Diadectidae and its Bearing on the Classification of Reptiles. Fieldiana: Geology 11, 1-53.

Pedersen, T. L. (2020). Ggforce: Accelerating 'ggplot2'. R Package Version-.2. doi:10.5194/wes-2020-31-ac1 Avabilable at: https://CRAN.R-project.org/ package=ggforce (Accessed February 01, 2021).

Reisz, R., and Baird, D. (1983). Captorhinomorph "stem" Reptiles from the Pennsylvanian Coal-Swamp deposit of Linton, Ohio. Ann. Carnegie Mus. Carnegie Mus. Nat. Hist. 52 (18), 393-411.

Reisz, R. (1972). Pelycosaurian Reptiles from the Middle Pennsylvanian of North America. Bull. Mus. Comp. Zoolog. 144 (2), 27-61.

Reisz, R. R., and Dilkes, D. W. (2003). Archaeovenator Hamiltonensis, a New Varanopid. (Synapsida: Eupelycosauria) from the Upper Carboniferous of Kansas. Can. J. Earth Sci. 40, 667-678. doi:10.1139/e02-063
Reisz, R. R., and Fröbisch, J. (2014). The Oldest Caseid Synapsid from the Late Pennsylvanian of Kansas, and the Evolution of Herbivory in Terrestrial Vertebrates. PLoS ONE 9 (4), e94518. doi:10.1371/journal.pone.0094518

Richards, E. J. (2016). The Ontogenetic Osteohistology of the Eureptile Captorhinus Aguti (Reptilia: Captorhinidae) and the Community Histology of the Early Permian Fissure-Fill Fauna Dolese Quarry. M.Sc. thesis. Toronto (ON): University of Toronto, 1-58.

Romer, A. S. (1956). Osteology of the Reptiles. Chicago: University of Chicago Press, $1-793$.

Rudis, B., Bolker, B., and Schulz, J. (2017). Ggalt: Extra Coordinate Systems, 'Geoms', Statistical Transformations, Scales and Fonts for 'ggplot2'. R Package Version 0.4.0. Avabilable at: https://CRAN.R-project.org/ package $=$ ggalt $($ Accessed February 01, 2021).

Shapiro, M. D., Shubin, N. H., and Downs, J. P. (2007). Limb Diversity and Digit Reduction in Reptilian Evolution, Fins into limbs: Evol. Dev. transformation, 225-245.

Spindler, F., Werneburg, R., Schneider, J. W., Luthardt, L., Annacker, V., and Rößler, R. (2018). First Arboreal 'pelycosaurs' (Synapsida: Varanopidae) from the Early Permian Chemnitz Fossil Lagerstätte, SE Germany, with a Review of Varanopid Phylogeny. PalZ 92 (2), 315-364. doi:10.1007/ s12542-018-0405-9

Thomson, T. J., and Motani, R. (2021). Functional Morphology of Vertebrate Claws Investigated Using Functionally Based Categories and Multiple Morphological Metrics, J. Morphol., 282, 449-471.

Venables, W. N., and Ripley, B. D. (2002). Modern Applied Statistics with S. Fourth Edition. New York: Springer. doi:10.1007/978-0-387-21706-2

Wickham, H. (2016). ggplot2: Elegant Graphics for Data Analysis. New York: Springer-Verlag.

Zani, P. A. (2000). The Comparative Evolution of Lizard Claw and Toe Morphology and Clinging Performance, J. Evol. Biol., 13 (2), 316-325.

Conflict of Interest: The authors declare that the research was conducted in the absence of any commercial or financial relationships that could be construed as a potential conflict of interest.

Copyright (c) 2021 Mann, Dudgeon, Henrici, Berman and Pierce. This is an openaccess article distributed under the terms of the Creative Commons Attribution License (CC BY). The use, distribution or reproduction in other forums is permitted, provided the original author(s) and the copyright owner(s) are credited and that the original publication in this journal is cited, in accordance with accepted academic practice. No use, distribution or reproduction is permitted which does not comply with these terms. 